\title{
The effects of grazing management in montado fragmentation and heterogeneity
}

Mara Almeida • Carla Azeda • Nuno Guiomar • Teresa Pinto-Correia

Keywords High Nature Value farmland _ Montado system _ Landscape fragmentation _ Landscape heterogeneity _ Grazing intensity

Abstract The Portuguese silvo-pastoral system montado is broadly classified as a High Nature Value (HNV) system since it corresponds to farmland hosting high biodiversity levels, and such biodiversity depends on specific land use practices. However, in recent decades a decline both in the total montado area and in the tree cover density within the montado has been observed, driven mainly by management changes. This decline may result in biodiversity loss. Grazing is a central aspect determining the long-term sustainability of the montado system and it has implications also on the montado structural diversity, particularly on connectivity and heterogeneity, which is crucial for the maintenance of montado HNV. The aim of this paper is to demonstrate how variations in montado structural diversity are correlated with grazing management and its implications on the value of the system for conservation. The empirical data derives from a case study composed of 41 montado farms in two municipalities of the Alentejo region. Data on grazing management, biophysical and spatial factors were collected and several metrics were calculated to assess montado fragmentation and heterogeneity. A multivariate analysis was performed using generalized additive models. Results show that different grazing patterns, depending on stocking density and grazing animal type, are correlated with variations in montado fragmentation and heterogeneity. Particularly, cattle's grazing is shown to have adverse effects on the montado fragmentation, while sheep grazing is shown to have stronger impacts on the heterogeneity within the montado patches. 